\title{
Vibration Analysis and Experimental Research of the Linear-Motor-Driven Water Piston Pump Used in the Naval Ship
}

\author{
Ye-qing Huang, ${ }^{1}$ Song-lin Nie, ${ }^{1}$ Hui Ji, ${ }^{1}$ and Shuang Nie $^{2}$ \\ ${ }^{1}$ Beijing Key Laboratory of Advanced Manufacturing Technology, Beijing University of Technology, Beijing 100124, China \\ ${ }^{2}$ Faculty of Applied Science and Engineering, University of Toronto, Toronto, ON, Canada M5S 1A4 \\ Correspondence should be addressed to Song-lin Nie; niesonglin@bjut.edu.cn
}

Received 3 March 2016; Accepted 22 June 2016

Academic Editor: Carlo Rainieri

Copyright (c) 2016 Ye-qing Huang et al. This is an open access article distributed under the Creative Commons Attribution License, which permits unrestricted use, distribution, and reproduction in any medium, provided the original work is properly cited.

\begin{abstract}
Aiming at the existing problems of traditional water piston pump used in the naval ship, such as low efficiency, high noise, large vibration, and nonintelligent control, a new type of linear-motor-driven water piston pump is developed and its vibration characteristics are analyzed in this research. Based on the 3D model of the structure, the simulation analyses including static stress analysis, modal analysis, and harmonic response analysis are conducted. The simulation results reveal that the mode shape under low frequency stage is mainly associated with the eccentricity swing of the piston rod. The vibration experiment results show that the resonance frequency of linear-motor-driven water piston pump is concentrated upon $500 \mathrm{~Hz}$ and $800 \mathrm{~Hz}$ in the low frequency range. The dampers can change the resonance frequency of the system to a certain extent. The vibration under triangular motion curve is much better than that of S curve, which is consistent with the simulation conclusion. This research provides an effective method to detect the vibration characteristics and a reference for design and optimization of the linear-motor-driven water piston pump.
\end{abstract}

\section{Introduction}

High-pressure water pump is one of important piece of equipment in ship engineering $[1,2]$. There are several kinds of high-pressure water pumps installed in cabins, such as bilge pump, drainage pump, seawater cooling pump, highpressure water mist pump, and desalination unit pump. Water axial piston pump is characterized by higher pressure, higher volumetric efficiency, and lower $p v$ values of the friction pairs in comparison with hydraulic gear and vane pumps [3-5]. However, the traditional axial piston pump driven by rotary motor has some intrinsic disadvantages. For example, it would produce the alternating axial impact forces acting on the cylinder and piston when the high and low pressure are switching and spread out through the swash plate and bearing. Owing to both rotary motion and reciprocating motion existing in conventional axial piston pump, they lead to a large amplitude and low frequency pressure pulsation. The pulsating force acts on the fluid not only in the pipe but also in the pump body, which would cause the axial rotation and lateral vibration of the piston pump. By analyzing mechanical disturbing force, it shows that the first-order overturning moment, first-order reciprocating inertia force, second-order reciprocating inertia moment, and centrifugal force exist in the pump set. The unbalance force produced by the mechanical motion and the effect of fluid pulsation would cause the fundamental frequency noise, second and third times harmonic noise. Those harmonic noises have aggregated most of the piston pump noise energy and determined a high total noise level. In order to overcome these shortcomings, the linear-motor-driven water piston pump is developed $[6,7]$. Compared with the traditional piston pump which can only regulate the rotor speed of the pump, the linear-motor-driven water piston pump can obtain a good flow output and vibration performance through changing its movement frequency.

Previously, several researchers studied the vibration characteristics of hydraulic piston pump/motor. Shin [8] investigated the dynamic behavior of the cylinder pressure considering a general system of a piston pump, a fluid power line, and end resistance. It was shown that the harmonic of maximum pulsation amplitude was related to the rotating 
frequency and discharge pressure of the pump. There have been efforts on understanding the vibration characteristics of axial piston pump and motor. Bahr et al. [9] studied the vibration characteristics of the pumping mechanism of constant power regulated swash plate axial piston pump by developing a mathematical model. Chen et al. [10-12] studied the dynamic vibration characteristics of the water fluid power piston motor. They also presented several methods for modeling and analyzing the vibration signals to diagnose the faults of water fluid power piston motor. Johansson et al. [13] studied noise characteristics which influence by the cross-angle in an axial piston pump. The experiments have verified that with the optimized cross-angle, the sound level is effectively reduced. Achten [14] studied the vibration characteristics of a variable displacement axial piston pump. The vibrating movement of the swash plate is measured and the experiments have shown the effects between swash plate vibration and the displacement of individual pistons.

Actually, the conventional rotary-motor-driven piston pump would produce unbalanced loading force and moment on the axis and cylinder body and is prone to causing large mechanical vibration and noise. With the rapid development of linear motor technology, more and more researchers have paid attention to the application of linear motor in the field of fluid transmission and control field. Early, the linear motor was used in artificial heart, single piston pump, pumping unit, air compressor, and so on. Yamada et al. [15] developed an artificial heart driven by linear pulse motor. The thrust/input power ratio of linear pulse motor was reached, $23.3 \mathrm{~N} / \mathrm{W}$, and then refreshed the linear pulse motor world record at that time. Mei and Goodall [16] presented a subsea hydraulic pump system that the overall system consists of two singlestage double-action reciprocating pumps, each of which is driven by two parallel connected double sided permanent magnet linear synchronous motors. Fully digital control had been realized and implemented in the simulation and also a number of control strategies had been tested. The results demonstrate that the steady state error of the linear motor is small and has good robustness against uncertainty. Zhang and Yang [17] studied the constant flow output working principle of double-action linear-motor-driven reciprocating pump and discuss the influence of motion interval of motors and lag angle of pump valve on the pulsation of systemic flow rates. Hou et al. [18] investigated the motion characteristics of three single-action and double-action linear motors driven reciprocating pump in theory. A motion law of uniform-acceleration, uniform velocity, and uniformdeceleration with phase difference of $60^{\circ}$ or $120^{\circ}$ is proposed to achieve theoretical constant flow rates. The development and application of smart materials also greatly promoted the development of the linear motor, which integrated the techniques of linear motor intelligent control and hydraulic pump design to achieve high efficiency and power density. Xiao et al. [19] developed a great thrust linear motor pumping unit to apply in the oil field. With the one-year running test, the results demonstrate that the system can accurately control the output power of the linear motor through intelligent control technology.

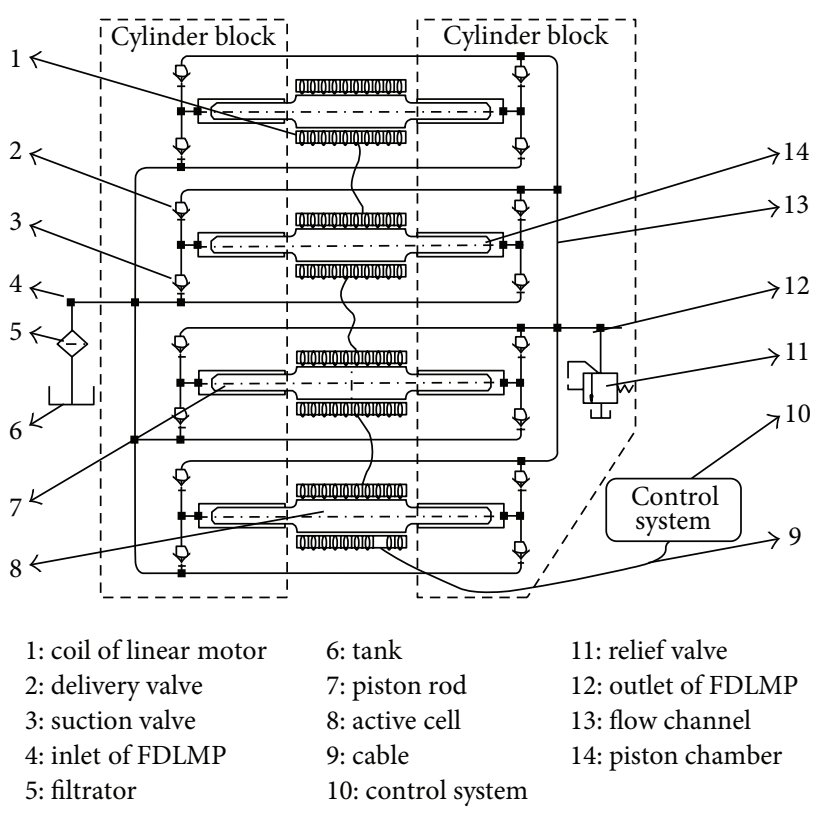

FIGURE 1: Schematic diagram of linear-motor-driven piston pump system.

Aiming at the existing problems of traditional piston pump used in the naval ship, such as low efficiency, high noise, large vibration, and nonintelligent control, a new type of linear-motor-driven water piston pump is developed and its vibration characteristics are analyzed in this research. Based on the 3D model of the structure, the simulation analysis including static stress analysis, modal analysis, and harmonic response analysis will be conducted, and then the stress diagram, the natural frequency, and the harmonic response spectrum of the pump system can be obtained. In order to optimize the linear motor motion, the motion characteristics under different motion curves and modes are explored. The vibration response characteristics of linearmotor-driven water piston pump will be investigated so as to avoid the resonance and reduce the system vibration.

\section{Configuration and Simulation Analysis}

The developed linear-motor-driven water piston pump is composed of four-group permanent magnet linear synchronous motor, two sets of highly integrated valve type piston pump units, and one set of servo control system. The schematic diagram of linear-motor-driven water piston pump is illustrated as in Figure 1. The linear motor active cell couples with piston by the self-aligning mechanism and drives the piston rod to reciprocate continuously with high frequency and high speed. For example, when the piston rod is driven by double-action linear motor reciprocate in certain velocity planning, one piston chamber (the left chamber) is in suction process, and the low pressure water goes through the suction valve to the piston chamber; meanwhile the other piston chamber (the right chamber) is in discharge process, and the water is compressed to high pressure and output from the delivery valve. 


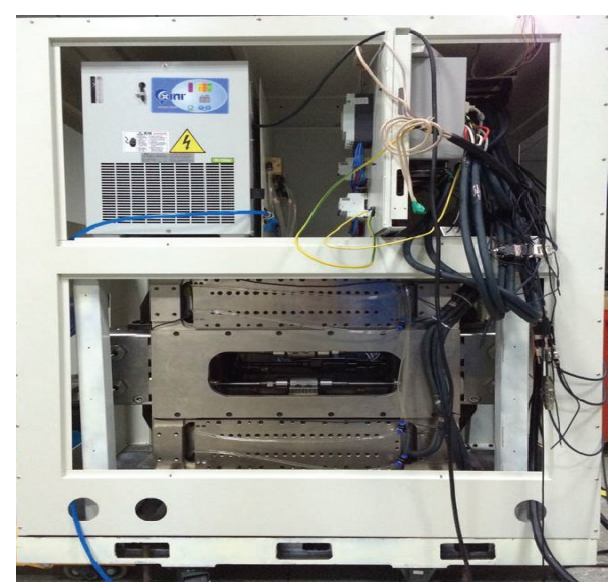

FIGURE 2: Linear-motor-driven water piston pump system.

Theoretically, the constant flow output of the linearmotor-driven water piston pump could effectively relieve the flow pulsation and pressure impact and lower the vibration of the pump. To achieve constant flow rate, the precise velocity property of single linear motor and the synchronization of multilinear motors are of significance. Therefore, four axes motion control strategy should be specifically investigated based on operation plan and numerical simulation to coordinate the operation phases of linear motors.

Furthermore, the piston pump only has one friction pair, which can improve the volumetric efficiency and is driven directly by linear motor, which can avoid the intermediate transmission mechanism and increase the mechanical efficiency. By means of the servo control system, the linearmotor-driven water piston pump can get good vibration characteristics and a sound flow output performance in comparison with the traditional water piston pump which can only regulate the movement by means of rotor speed control.

2.1. Static Analysis. The linear-motor-driven water piston pump (as shown in Figure 2) includes linear motors, water hydraulic piston pump section, and servo control system. In order to reduce the mechanical vibration of the pump system, the static simulation analysis is used to evaluate the stresses, strains, displacements, and forces in the mechanical components of the pump system.

The water hydraulic piston pump section is comprised of two large cylinders, eight distributing valves, and eight pistons. The simplified 3D model of the water hydraulic piston pump is built by the software SolidWorks. As shown in Figure 3, without affecting the static analysis results of main structure, the linear motor and the other unnecessary components are ignored in the simplified 3D model. The material of cylinder block is $316 \mathrm{~L}$ stainless steel, and the piston sleeve is made of aluminum bronze. Obviously, it is easy to obtain the physical properties of these materials such as Young's modulus, Poisson's ratio, bulk modulus, and shear modulus.

In the case of normal operation condition, the rated pressure of linear-motor-driven water piston pump is $6 \mathrm{MPa}$

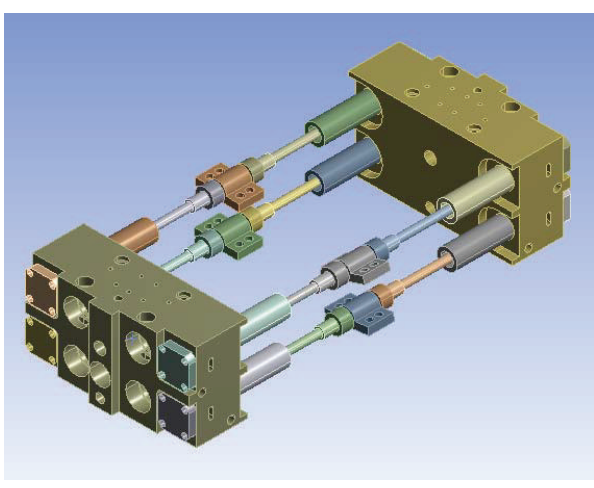

FIGURE 3: Simplified 3D model of hydraulic piston pump section.

and the thrust output of each linear motor reaches $5 \mathrm{KN}$. The results of static analysis are illustrated in Figure 4. It can be seen from Figure 4 that the maximum deformation is close to $0.15 \mathrm{~mm}$ which is far less than the dimensions of the mechanical structure, and it occurs at the joint between linear motor and piston. Similarly, the maximum equivalent stress is about $95.398 \mathrm{MPa}$, which is also lower than the yield strength of the material. It means that the mechanical structure of the piston pump can sustain normal operation loading condition.

2.2. Modal Analysis. Modal is the natural characteristics of the mechanical structure. Each modal has its special characteristics including natural frequency, mode shape, and damping ratio [20]. Modal analysis is generally employed to deal with the vibration response of mechanical structure, and the modal parameters can be obtained by calculation or test analysis. By the modal analysis method to figure out each order modal characteristic of the structure in the susceptible frequency range, it is possible to predict the actual vibration response under action of various external or internal vibration sources.

Generally, for a relatively simple system, the modal parameters and system response could be obtained by mathematical method; for a complex system studied in this paper, excessive simplification will lead to the results of calculation not being consistent with actual. For the complex vibration analysis, many methods such as finite element analysis, operational modal analysis, and experimental modal analysis could be applied. While in traditional experimental modal analysis, the forces exciting test sample is controlled, and the testing is conducted in the laboratory. In operational modal analysis, the forces are just the ones which are naturally presented during the operation of the structure [21]. However, either the operational modal analysis method or the experimental modal analysis method needs a large amount test equipment and experimental data as a foundation [22]. Therefore, the finite element analysis method is adopted in this study to obtain the system natural frequencies and mode shapes.

For a multidegree of freedom forced vibration system, the motion equation can be expressed as

$$
M\{\ddot{\chi}\}+C\{\dot{\chi}\}+K\{\chi\}=\{F(t)\} .
$$




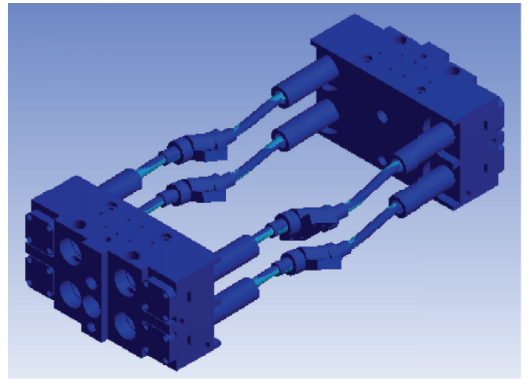

(a) Stress diagram

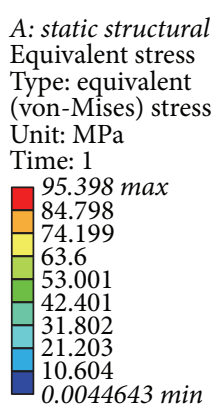

$0.0044643 \mathrm{~min}$

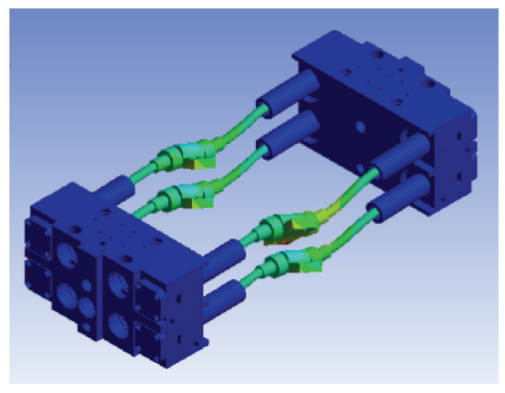

A: static structural Total deformation Type: total deformation Unit: $\mathrm{mm}$ Time: 1

(b) Deformation diagram

FIGURE 4: Stress and deformation diagram.

With the coordinate transformation $\{\chi\}=[u]\{q\}$, substitute it into (1), where

$$
\bar{M}\{\ddot{q}\}+C_{p}\{\dot{q}\}+\bar{K}\{q\}=u^{T}\{F(t)\},
$$

where $C_{p}$ is the modal damping matrix.

In the case of proportional damping, there is $C=\alpha M+$ $\beta K$, so the modal damping matrix can be written as

$$
\begin{aligned}
C_{p} & =u^{T}[\alpha M+\beta K] u=\alpha u^{T} M u+\beta u^{T} K u \\
& =\alpha \bar{M}+\beta \bar{K} .
\end{aligned}
$$

Substitution of (3) into (2):

$$
\begin{array}{r}
M_{r} \ddot{q}_{r}+\left(\alpha M_{r}+\beta K_{r}\right) \dot{q}_{r}+K_{r} q_{r}=N_{r}(t) \\
\quad(r=1,2, \ldots, n),
\end{array}
$$

where $N_{r}(t)=u^{T}\{F(t)\}$.

Make the $r$ th-order modal damping $C_{r}=\alpha M_{r}+\beta K_{r}$, substituting into (4):

$$
\ddot{q}_{r}+2 \zeta_{r} \omega_{n r} \dot{q}_{r}+\omega_{n r}^{2} q_{r}=\frac{N_{r}(t)}{M_{r}} \quad(r=1,2, \ldots, n),
$$

where $\zeta$ is damping ratio and defined as dimensionless quantity

$$
\zeta_{r}=\frac{C_{r}}{2 M_{r} \omega_{n r}}=\frac{\alpha M_{r}+\beta K_{r}}{2 M_{r} \omega_{n r}}=\frac{\alpha+\beta \omega_{n r}}{2 \omega_{n r}} .
$$

In the case of nonproportional damping, the key problem of (2) is the diagonalization of $C_{p}$; otherwise, the coordinate transformation equation is still very difficult to solve. General engineering problems often difficultly meet the requirements. Under the condition of satisfying the engineering precision, it is assumed that the modal damping matrix can be turned into a diagonal matrix. The external force acting on the system is expressed as

$$
\{F(t)\}=\{F\} \sin \omega t
$$

The external force can be represented in the plural form as

$$
\begin{aligned}
F(t) & =F \sin \omega t=F e^{j \omega t}, \\
u^{T} F(t) & =N e^{j \omega t} .
\end{aligned}
$$

Substitution of (8) into (2):

$$
\begin{gathered}
M_{1} \ddot{q}_{1}+c_{11} \dot{q}_{1}+c_{12} \dot{q}_{2}+\cdots+c_{1 n} \dot{q}_{n}+K_{1} q_{1}=N_{1} e^{j \omega t} \\
\vdots \\
M_{n} \ddot{q}_{n}+c_{n 1} \dot{q}_{1}+c_{n 2} \dot{q}_{2}+\cdots+c_{n n} \dot{q}_{n}+K_{n} q_{n}=N_{n} e^{j \omega t} .
\end{gathered}
$$

Assuming that the natural frequencies are not very close and the damping is small, then (1) if any external force frequency is not close to natural frequency, the main role is the inertia force and the external force; the damping force can be neglected; (2) if the frequency of external force is close to the $r$ th-order natural frequency, the $r$ th equation is written as

$$
\begin{aligned}
& M_{r} \ddot{q}_{r}+c_{r 1} \dot{q}_{1}+c_{r 2} \dot{q}_{2}+\cdots+c_{r r} \dot{q}_{r}+c_{r n} \dot{q}_{n}+K_{r} q_{r} \\
& \quad=N_{r} e^{j \omega t} .
\end{aligned}
$$

Because the generalized velocity $\dot{q}_{r}$ at this time is much larger than that of other generalized velocities, the other damping forces can be neglected. $c_{r r} \dot{q}_{r}$ is the only one damping term which needs to be considered ( $c_{r r}$ is a diagonal term). The viscous damping model is an approximate treatment method, ignoring the influence of the nondiagonal entries which are equal to increase the response. Thus, this kind of treatment method should be safe.

Back to (2), assuming that the damping matrix is diagonal matrix, it could be written as

$$
M_{i} \ddot{q}_{i}+C_{i} \dot{q}_{i}+K_{i} q_{i}=u_{i}^{T} F e^{j \omega t} \quad(i=1,2, \ldots, n) .
$$

The coordinates of generalized coordinate system $q_{i}$ are expressed as

$$
q_{i}=Q_{i} e^{j \omega t} .
$$

Substitution of (12) into (11):

$$
\left(-\omega^{2} M_{i}+j \omega C_{i}+K_{i}\right) Q_{i} e^{j \omega t}=u_{i}^{T} F e^{j \omega t} .
$$

And it could be obtained that

$$
Q_{i}=\frac{u_{i}^{T} F}{K_{i}-\omega^{2}+j \omega_{i} C_{i}}=\frac{u_{i}^{T} F}{K_{i}\left[\left(1-r_{i}^{2}\right)+2 j \zeta_{i} r_{i}\right]},
$$

where $r_{i}=\omega / \omega_{n i}$ is frequency ratio and $\zeta_{i}=C_{i} / 2 \sqrt{K_{i} M_{i}}$ is damping ratio. 
Therefore, the response expression of the system can be obtained:

$$
\begin{aligned}
\chi & =u q=\left[\{u\}_{1},\left\{u_{2}\right\}, \ldots,\{u\}_{n}\right]\left\{\begin{array}{c}
q_{1} \\
q_{2} \\
\vdots \\
q_{n}
\end{array}\right\}=\sum_{i=1}^{n} q_{i}\{u\}_{i} \\
& =\sum_{i=1}^{n} \frac{u_{i}^{T} F u_{i} e^{j \omega t}}{K_{i}\left[\left(1-r_{i}^{2}\right)+j 2 \zeta_{i} r_{i}\right]} .
\end{aligned}
$$

When the system is only excited at the $j$ th coordinate,

$$
\chi=\sum_{i=1}^{n} \frac{u_{j i} F_{j} u_{i} e^{j \omega t}}{K_{i}\left[\left(1-r_{i}^{2}\right)+j 2 \zeta_{i} r_{i}\right]},
$$

where $u_{j i}$ represents the value of $j$ th coordinates corresponding to the $i$ th-order mode shape.

Similarly, the response of any coordinates $\chi_{k}$ is expressed as

$$
\chi_{k}=\sum_{i=1}^{n} \frac{u_{j i} u_{k i} F_{j} e^{j \omega t}}{K_{i}\left[\left(1-r_{i}^{2}\right)+j 2 \zeta_{i} r_{i}\right]} .
$$

Equation (17) uses modal parameters to describe the vibration response, and the real response can be obtained by solving the imaginary part. Because of that,

$$
\begin{aligned}
\frac{1}{\left(1-r_{i}^{2}\right)+j 2 \zeta_{i} r_{i}} & =\frac{\left(1-r_{i}^{2}\right)-j 2 \zeta_{i} r_{i}}{\left(1-r_{i}^{2}\right)^{2}+4 \zeta_{i}^{2} r_{i}^{2}} \\
& =\frac{1}{\sqrt{\left(1-r_{i}^{2}\right)^{2}+4 \zeta_{i}^{2} r_{i}^{2}}} e^{-j \varphi_{i}},
\end{aligned}
$$

where $\varphi_{i}=\operatorname{tg}^{-1}\left(2 \zeta_{i} r_{i} /\left(1-r_{i}^{2}\right)\right)$.

Substitution into (17):

$$
\chi_{k}=\sum_{i=1}^{n} \frac{u_{j i} u_{k i} F_{j} e^{j\left(\omega t-\varphi_{i}\right)}}{K_{i} \sqrt{\left(1-r_{i}^{2}\right)^{2}+4 \zeta_{i}^{2} r_{i}^{2}}},
$$

where $\varphi_{i}=\operatorname{tg}^{-1}\left(2 \zeta_{i} r_{i} /\left(1-r_{i}^{2}\right)\right)$, and the imaginary part could be written as

$$
\begin{aligned}
& \sum_{i=1}^{n} \frac{u_{j i} u_{k i} F_{j}}{K_{i} \sqrt{\left(1-r_{i}^{2}\right)^{2}+4 \zeta_{i}^{2} r_{i}^{2}}} \sin \left(\omega t-\varphi_{i}\right) \\
& \quad=\chi_{k} \sin \left(\omega t-\varphi_{i}\right) .
\end{aligned}
$$

Considering that the influence of high-order modal is smaller than low-order one, the fore ten-order modal is the focus of this research and the modal analysis will be conducted by finite element calculation based on the theory analysis mentioned above. As the water piston pump section bears certain loading under normal operating condition, the prestress modal analysis could be more precisely compared
TABLE 1: The fore ten modes of vibration.

\begin{tabular}{lcc}
\hline Modes & Frequency $(\mathrm{Hz})$ & Modal deformation $(\mathrm{mm})$ \\
\hline 1 & 166.19 & 18.339 \\
2 & 166.38 & 14.080 \\
3 & 166.50 & 17.310 \\
4 & 166.59 & 18.448 \\
5 & 166.87 & 17.263 \\
6 & 167.27 & 18.570 \\
7 & 167.46 & 19.287 \\
8 & 167.84 & 19.253 \\
9 & 380.25 & 43.912 \\
10 & 382.62 & 44.080 \\
\hline
\end{tabular}

with the free modal analysis. By modal extraction method of Block Lanczos (as shown in Figure 5), the first to tenth natural frequencies and mode shapes of hydraulic piston pump section are gained.

Table 1 shows the fore ten-order modal frequencies and corresponding deformation values of each order natural frequency. From the modal analysis results, it is demonstrated that the first-order natural frequency is close to $166.19 \mathrm{~Hz}$, which is larger than the system motion frequency $(3 \mathrm{~Hz})$, and the modal deformation is about $18.3 \mathrm{~mm}$. Due to the large body mass and low natural frequency of the cylinder block, the resonance of low frequency stage easily occurs at the joint between the linear motor and piston. From Figure 5, it can be seen that the mode shape under low frequency stage is mainly associated with the eccentricity swing of the piston rod and the maximum modal deformation is within the acceptable range. The eccentricity swing of piston rod would cause the unbalanced force and vibration as well as the wear failure of the piston. Thus, to avoid the eccentricity swing of piston rod, the joint design should be optimized.

2.3. Harmonic Analysis. Harmonic response analysis (including frequency response analysis and frequency sweep analysis) is mainly used to analyze the steady state response of linear structure according to the harmonic loading. The vibration harmonic response analysis method could reveal the relationships between the frequency, displacement, velocity, and acceleration under different frequency [23].

In order to evade the resonance and fatigue, avoiding the excitation frequency is one of effective ways. The input load of the harmonic response analysis is a sinusoidal load which is changing by the time. The primary characteristic values of the load are frequency and amplitude, while the load form can be defined as force, pressure, and the displacement. Generally, the simulation results are usually the displacement, stress, and strain. By analyzing the output curve, the peak response frequency and amplitude can be obtained, which can be used as the basis of the vibration mechanism analysis and vibration reduction design.

In a typical multiple degree of freedom system, the dynamic equation is given by

$$
M\{\ddot{x}\}+C\{\dot{x}\}+K\{x\}=F(t),
$$




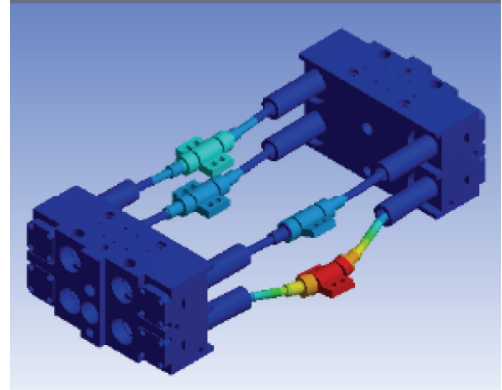

B: modal

Total deformation

Type: total deformation

Frequency: $166.19 \mathrm{~Hz}$

Unit: $\mathrm{mm}$

$18.339 \max$

$\left[\begin{array}{r}18.339 \\ -16.301 \\ -14.264 \\ -12.226 \\ -10.188 \\ -8.1507 \\ -6.113 \\ -4.0753 \\ 2.0377 \\ -0 \mathrm{~min}\end{array}\right.$

(a) The 1st-order vibration mode diagram

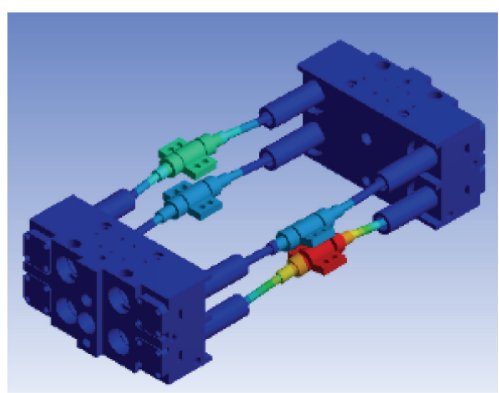

B: modal

Total deformation 3

Type: total deformation

Frequency: $166.5 \mathrm{~Hz}$

Unit: $\mathrm{mm}$

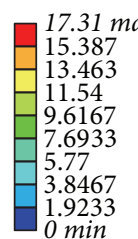

(c) The 3rd-order vibration mode diagram

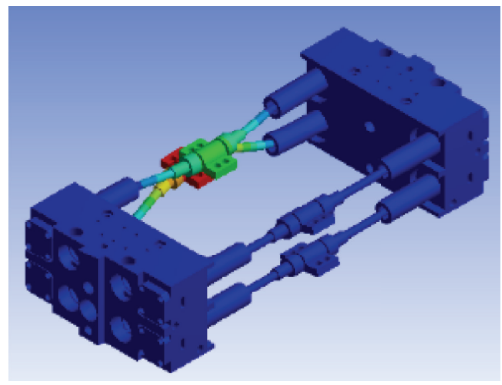

B: modal

Total deformation 5

Type: total deformation

Frequency: $166.87 \mathrm{~Hz}$

Unit: $\mathrm{mm}$

\begin{tabular}{|l}
17.263 max \\
-15.345 \\
-13.427 \\
11.509 \\
-9.5905 \\
-7.6724 \\
-5.7543 \\
-3.8362 \\
1.9181 \\
0 min
\end{tabular}

(e) The 5th-order vibration mode diagram

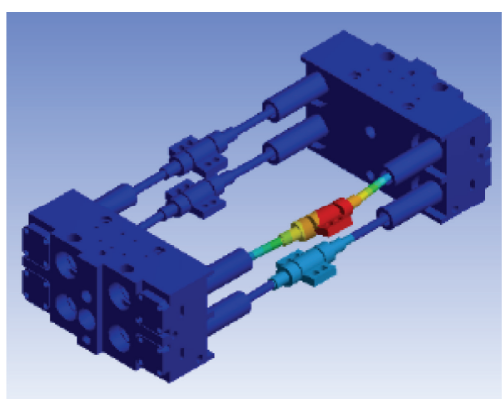

B: modal

Total deformation 7

Type: total deformation Frequency: $167.46 \mathrm{~Hz}$

Unit: $\mathrm{mm}$

\begin{tabular}{|l}
19.287 max \\
-17.144 \\
-15.001 \\
12.858 \\
10.715 \\
8.5719 \\
6.4289 \\
4.286 \\
2.143 \\
0 min
\end{tabular}

(g) The 7th-order vibration mode diagram

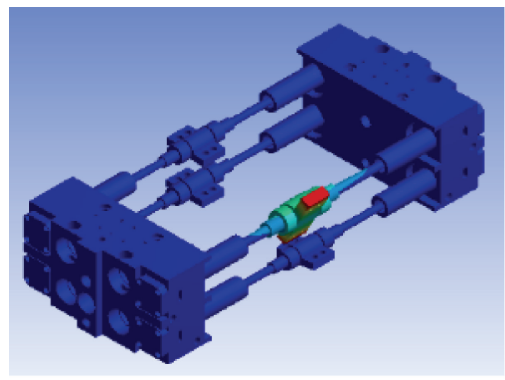

B: modal

Total deformation 9

Type: total deformation

Frequency: $380.25 \mathrm{~Hz}$

Unit: $\mathrm{mm}$

$43.912 \max$
-39.033
-34.154
-29.275
24.395
-19.516
-14.637
-9.7582
4.8791
0 min

(i) The 9th-order vibration mode diagram

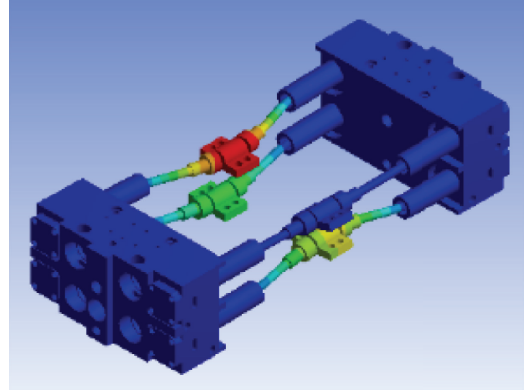

B: modal

Total deformation 2

Type: total deformation

Frequency: $166.38 \mathrm{~Hz}$

Unit: $\mathrm{mm}$

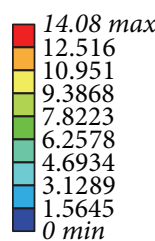

(b) The 2nd-order vibration mode diagram

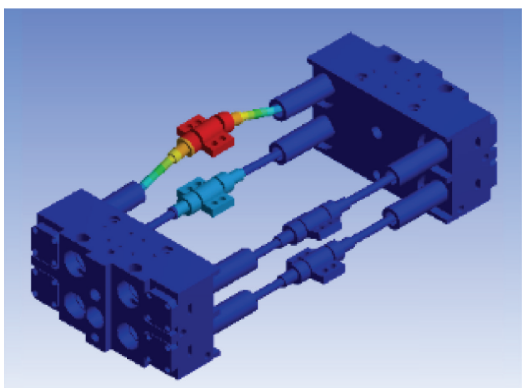

B: modal

Total deformation 4

Type: total deformation Frequency: $166.59 \mathrm{~Hz}$

Unit: $\mathrm{mm}$

\begin{tabular}{|l}
$18.448 \max$ \\
-16.398 \\
-14.348 \\
-12.298 \\
-10.249 \\
-8.1989 \\
-6.1492 \\
4.0995 \\
2.0497 \\
$0 \mathrm{~min}$
\end{tabular}

(d) The 4th-order vibration mode diagram

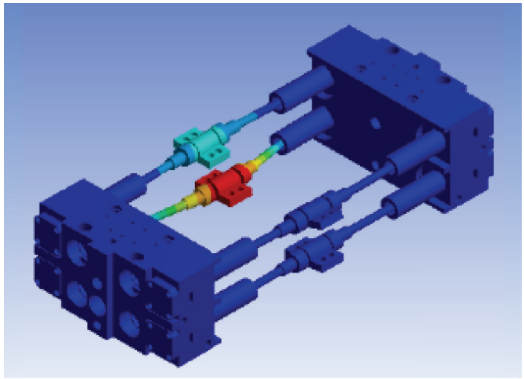

B: modal

Total deformation 6

Type: total deformation Frequency: $167.27 \mathrm{~Hz}$

Unit: $\mathrm{mm}$

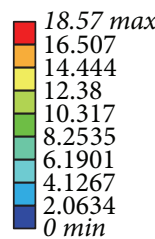

(f) The 6th-order vibration mode diagram

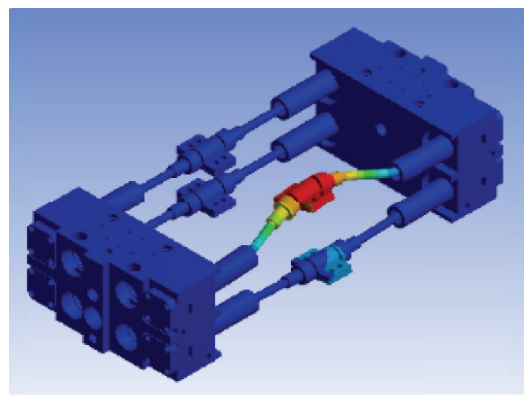

B: modal

Total deformation 8

Type: total deformation Frequency: $167.84 \mathrm{~Hz}$

Unit: $\mathrm{mm}$

\begin{tabular}{|l}
19.253 max \\
-17.114 \\
-14.975 \\
-12.836 \\
-10.696 \\
8.557 \\
-6.4178 \\
4.2785 \\
2.1393 \\
$0 \mathrm{~min}$
\end{tabular}

(h) The 8th-order vibration mode diagram

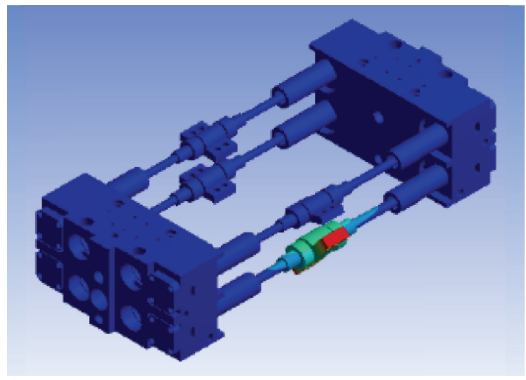

B: modal

Total deformation 10

Type: total deformation

Frequency: $382.62 \mathrm{~Hz}$

Unit: $\mathrm{mm}$

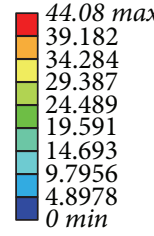

(j) The 10th-order vibration mode diagram

FIGURE 5: The fore ten-order mode shapes and natural frequencies. 


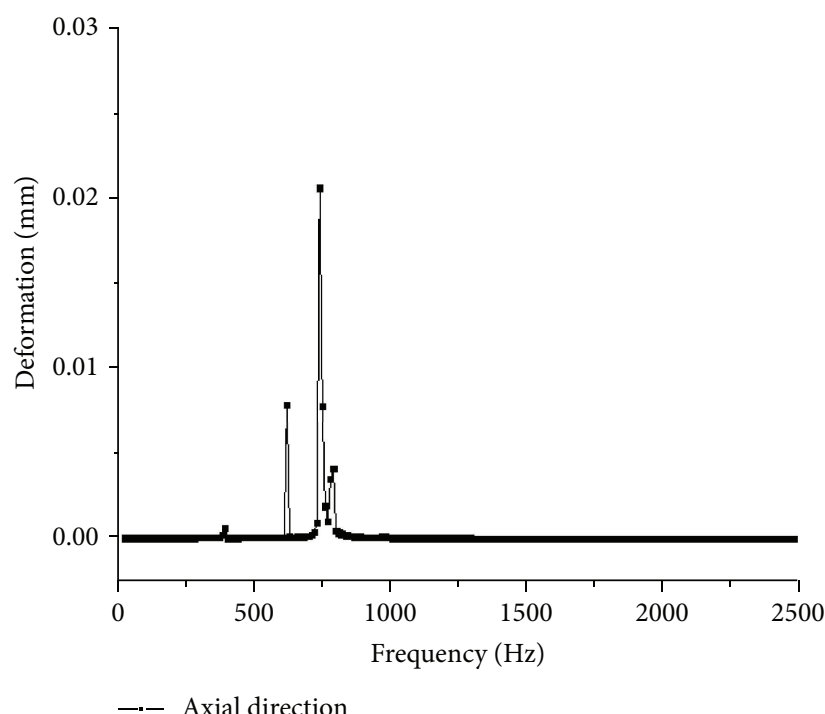

(a) Deformation of cylinder wall in axial direction

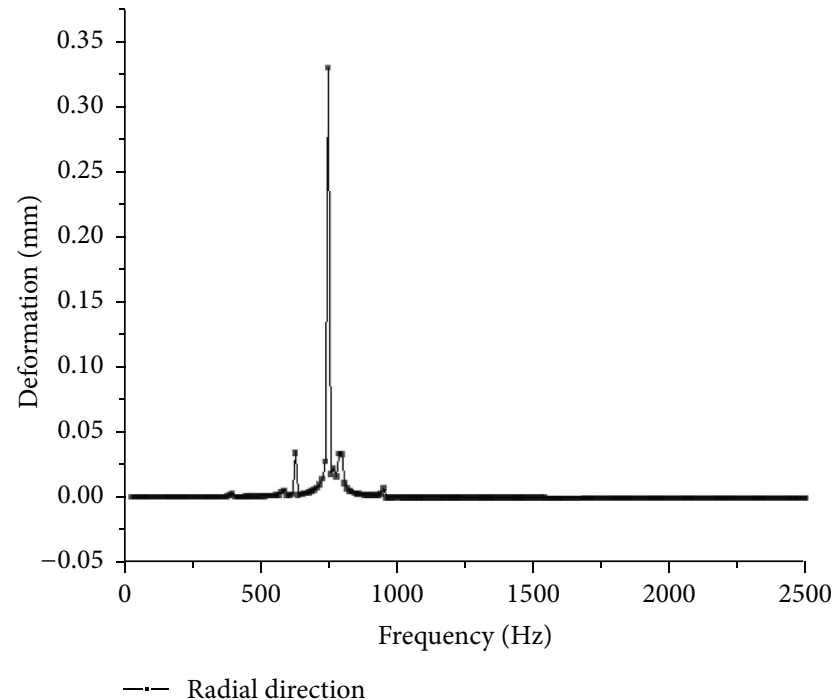

(b) Deformation of cylinder wall in radial direction

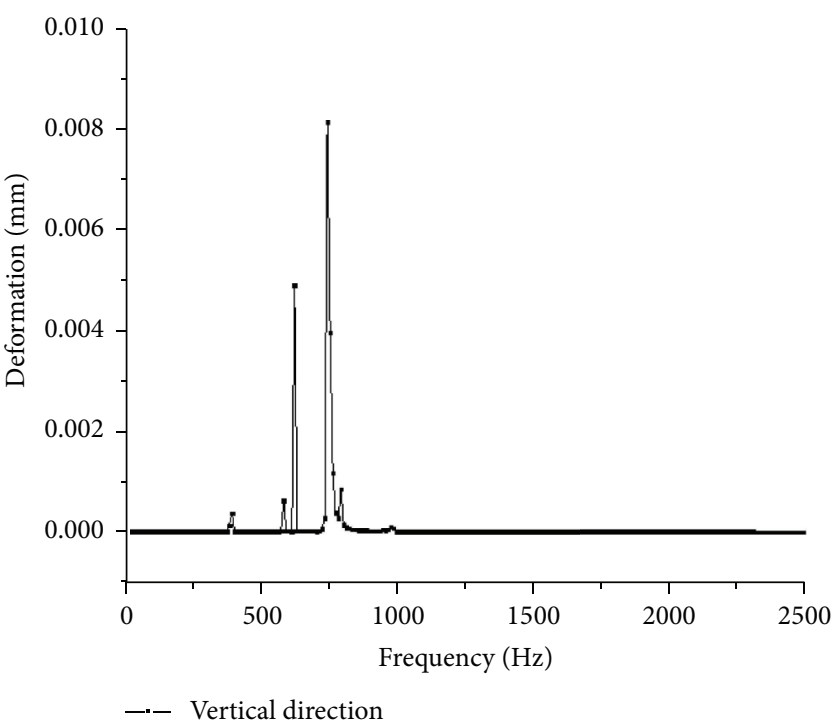

(c) Deformation of cylinder wall in vertical direction

FIGURE 6: Deformation-frequency diagrams.

where $M$ is the mass matrix, $C$ is the damping matrix, $K$ is the stiffness matrix, $\{\ddot{x}\}$ is the acceleration vector, $\{\dot{x}\}$ is the velocity vector, $\{x\}$ is the displacement vector, and $F$ is the load vector.

For different research purposes, it can be used to solve the different problem based on formula (21). For instance, when assuming that the load vector and damping matrix is zero, the eigenvalue of formula (21) is obtained and according to the eigenvalue the vibration mode and natural frequency can be analyzed, while the harmonic analysis is solving the structure response at the assumption that the input load is harmonic circulation which means $F(t)=F_{0} \sin (\omega t)$. In this research, mode superposition method is applied for harmonic analysis of the linear-motor-driven water piston pump based on ANSYS Workbench. The amplitude of exciting force is close to the linear motor thrust output force, namely, $5 \mathrm{KN}$, while the frequency range is from 10 to $2500 \mathrm{~Hz}$. The cylinder wall is selected as the study surface which is convenient for the following experimental verification. The simulation results are shown in Figure 6.

The three figures present the modal deformation of axial direction (the motion direction of linear motor), radial direction (perpendicular to the linear motor motion direction in the horizontal plane), and vertical direction, respectively. From Figure 6, it can be seen that the maximum modal deformation occurs in the radial direction and catastrophic failure is not obverse in the structure. The bottom of cylinder is set as fixed support in simulation; the vibration amplitude is smaller in the vertical direction. In the case that the sinusoidal excitation force is $5 \mathrm{KN}$, the maximum modal deformation is $0.33 \mathrm{~mm}$, and the phase angle is -163.11 degrees. The maximum stress is about $33.3 \mathrm{MPa}$ occurring in the vertical 
direction, and it does not exceed the yield strength of the material.

On the other hand, the simulation results demonstrate that the resonance frequencies of the linear-motor-driven water piston pump mainly concentrated under $500-800 \mathrm{~Hz}$. Because the motion frequency of the pump is about $3 \mathrm{~Hz}$ and the mass is large, the resonance does not easily occur under the low frequency stage. Thus, when debugging the parameters of linear motor, the resonance frequency should also be avoided. The harmonic analysis provides a method to predict the dynamic characteristic of structure, which can help to overcome the harmful effects caused by fatigue, resonance, and other forced vibration. Before the system vibration testing, the PID parameter adjustment of linear motor should be carried out. In the next section, the experiment will be conducted to verify the harmonic response analysis.

\section{Vibration Test and Results Analysis}

3.1. Parameters Debugging of the System. The vibration characteristics of the linear-motor-driven water piston pump are affected by several factors, such as mechanical structure and servo control system. Compared with the single control mode of traditional piston pump, the servo control system of the linear-motor-driven water piston pump is able to perform a variety of servo control modes. The spline (i.e., spline interpolation algorithm) and PVT (i.e., location-time interpolation algorithm) motion mode are the most widely used motion modes of the linear motor. In the spline motion mode, the movement distance is divided into equal segments by the time and only needs to define the position of the coordinate points at the time of operation. The advantage of this method is that it can reduce the workload and facilitate the calculating. The PVT motion mode needs to define the distance, velocity, and move time at the end of each step. Therefore, it has higher request for computing performance of the servo control system in comparison with the spline motion mode.

Since the piston is directly connected with the linear motor, the instantaneous flow rate of the system is proportional to the piston instantaneous effective velocity. Thus, the property parameters of linear motor, such as the following errors, will eventually affect the performance of linear-motordriven water piston pump. In order to make the pump get steady flow output and achieve the goal of low vibration and noise, it should set the servo control characteristic parameters of linear motor appropriately. The influencing factors of servo control characteristics include not only the motion mode but also the movement curve. Usually the motion curves are triangular wave and $\mathrm{S}$ wave curve.

The velocity mathematic model of triangle wave planning in the time domain of $[0, T]$ is described as follows:

$$
g(t)= \begin{cases}\frac{4 A}{T} t & t \leq \frac{T}{4} \\ -\frac{4 A}{T} t+2 A & \frac{T}{4}<t \leq \frac{3 T}{4} \\ \frac{4 A}{T} t-4 A & \frac{3 T}{4}<t \leq T\end{cases}
$$

where $A$ is the speed amplitude of linear motor.
TABLE 2: The following errors under different modes and curves.

\begin{tabular}{lcc}
\hline & $\begin{array}{c}\text { Maximum following } \\
\text { errors (cts) }\end{array}$ & $\begin{array}{c}\text { Average following } \\
\text { errors (cts) }\end{array}$ \\
\hline PVT/triangle curve & 148.1 & 51.0 \\
PVT/S curve & 155.3 & 54.6 \\
Spline/triangle curve & 149.6 & 51.5 \\
Spline/S curve & 150.0 & 56.3 \\
\hline
\end{tabular}

Note: $1 \mathrm{cts}=0.5 \mu \mathrm{m}$.

The velocity mathematic model of $S$ wave planning in the time domain of $[0, T / 2]$ is given by

$$
\begin{aligned}
& g(t) \\
& \quad \begin{cases}\frac{1}{2} J t^{2} & 0 \leq t \leq T_{1} \\
v_{1}+a\left(t-T_{1}\right) & T_{1} \leq t \leq T_{2} \\
v_{2}+a\left(t-T_{2}\right)-\frac{1}{2} J\left(t-T_{2}\right)^{2} & T_{2} \leq t \leq T_{3} \\
v_{3}-\frac{1}{2} J\left(t-T_{3}\right)^{2} & T_{3} \leq t \leq T_{4} \\
v_{4}-a\left(t-T_{4}\right) & T_{4} \leq t \leq T_{5} \\
v_{5}-a\left(t-T_{5}\right)+\frac{1}{2} J\left(t-T_{5}\right)^{2} & T_{5} \leq t \leq T_{6}\end{cases}
\end{aligned}
$$

where $a$ and $J$ are the constants and $v_{1}, v_{2}, v_{3}, v_{4}$, and $v_{5}$ are the speeds of each interval, respectively. Once the acceleration time, uniform motion time, one-way movement distance, and motion period are determined, the whole motion process can be derived. For the working condition of the linear-motordriven water piston pump, when the four-group linear motor move at the phase difference of 90 degrees, respectively, it could reach the constant flow output theoretically.

For the sake of obtaining the best running state, the dynamic response characteristics of the linear motor under different motion modes and motion curves have been conducted in the simulation system. The debugging results of the linear motor in simulation mode under different motion modes and curves are shown in Figure 7.

In the coordinate system, the horizontal axis represents time and the unit is the second, while the longitudinal axes represent the velocity and following error, and the measuring units are cts/s and cts (cts is the counting unit of grating, and it depends on the resolution of grating; here one cts is equal to $0.5 \mu \mathrm{m}$ ), respectively. From the debugging results (as shown in Table 2), it can be seen that the simulation results are similar and can meet the normal operation under different conditions. The better working condition is the triangle curve under PVT motion mode. The average following error is close to $51.0 \mathrm{cts}$ and the maximum following error is $148.1 \mathrm{cts}$. The following error of linear motor under triangle curve is lesser than that of S curve. Obviously, appropriate motion mode and curve could effectively reduce the following error to control the actual motion track precisely and then to lower the vibration of the pump. 


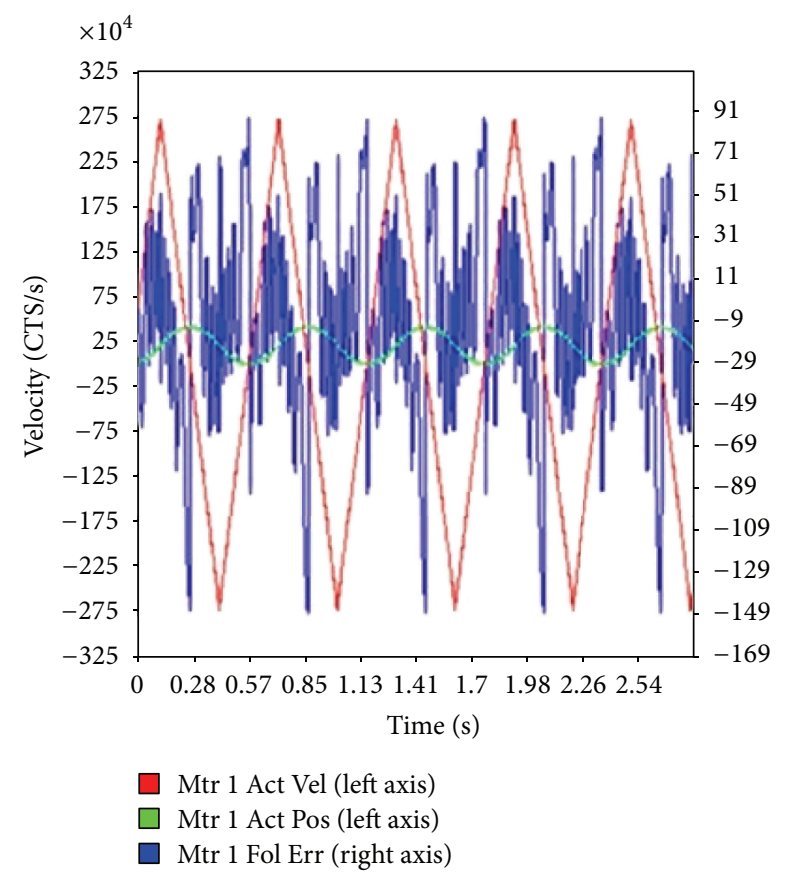

(a) Triangle velocity curves of linear motor at PVT mode

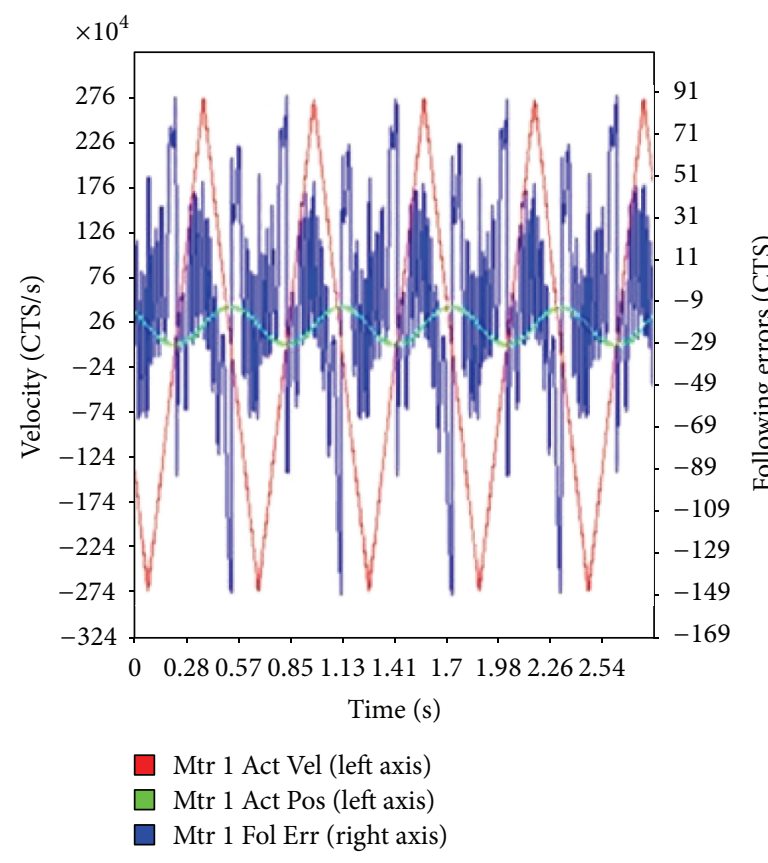

(c) Triangle velocity curves of linear motor at spline mode

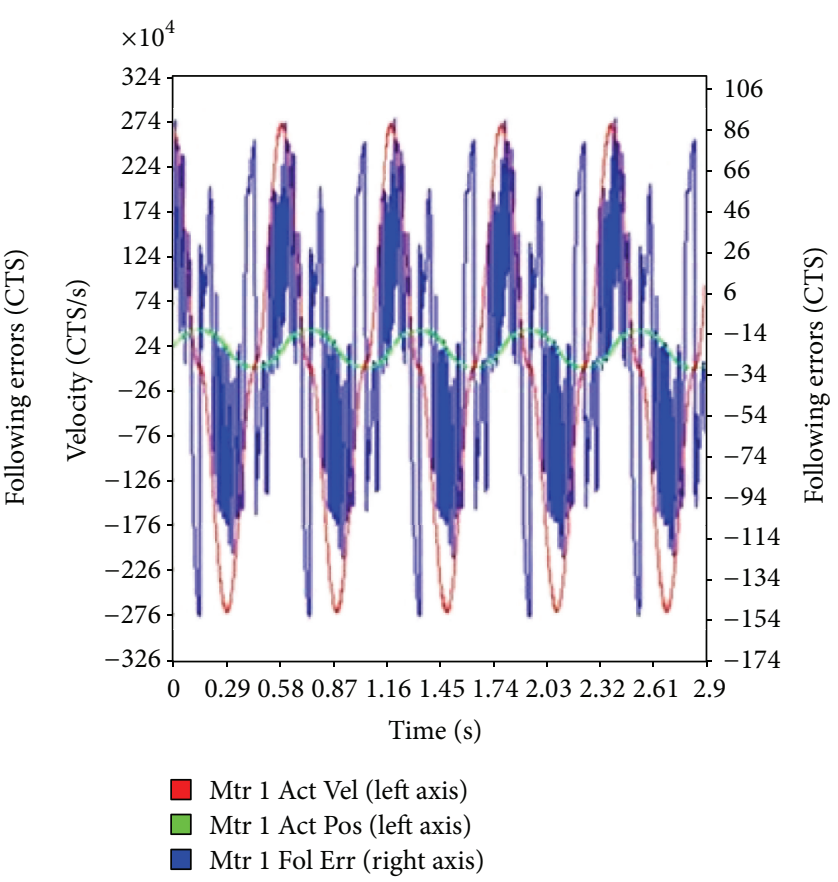

(b) S velocity curves of linear motor at PVT mode

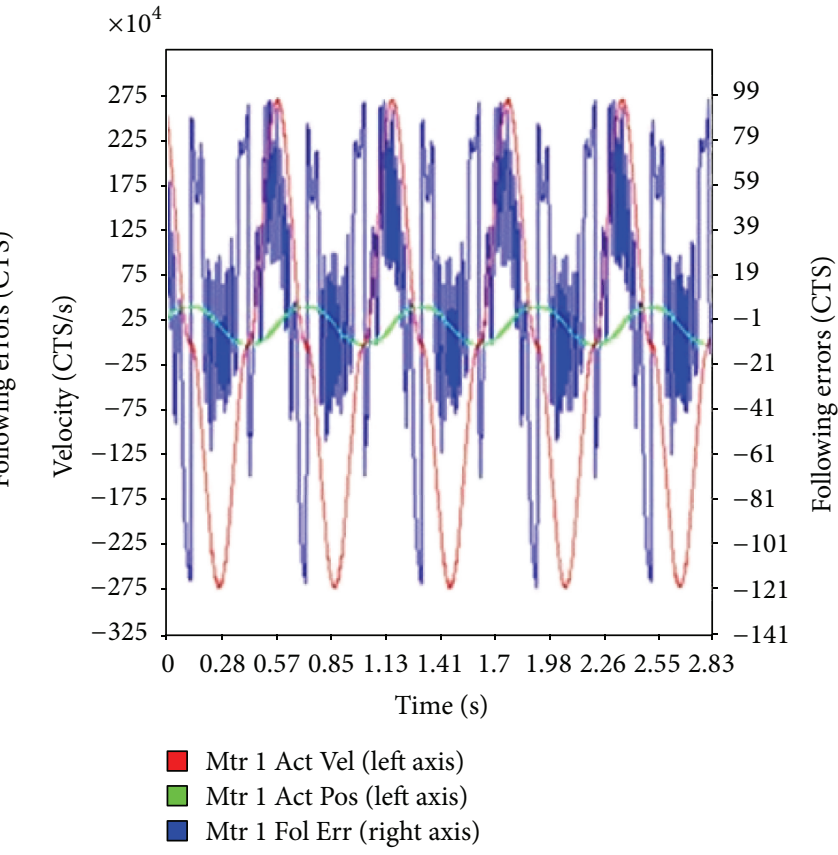

(d) S velocity curves of linear motor at spline mode

FIgURE 7: Debugging diagram under different motion modes and curves.

3.2. Vibration Experiment. The vibration source of the linearmotor-driven water piston pump mainly comes from the motion of mechanism and the flow pulsation noise. The main effect factors of the vibration response characteristics in this pump are the response lag of distributing valve and synchronous phase error of linear motor. Therefore, under the certain system structure parameters, the control strategy of linear motor has become the key factor for influencing the system vibration characteristics. On the basis of the above simulation analysis, the vibration experiment is conducted to obtain the vibration and noise information.

As shown in Figure 8, the cylinder wall is chosen as the test object. The three channels gather the vibration signal of $x$-axis (the motion direction of linear motor), $y$-axis (perpendicular to the linear motor motion direction in the horizontal plane), and $z$-axis (vertical direction), respectively. 
TABLE 3: Vibration amplitude of each channel under the triangle wave motion curve.

\begin{tabular}{lcc}
\hline Signal channel & $\begin{array}{c}\text { Maximum amplitude } \\
(\mu \mathrm{m})\end{array}$ & $\begin{array}{c}\text { Minimum amplitude } \\
(\mu \mathrm{m})\end{array}$ \\
\hline 1 & 413.2 & -454.0 \\
2 & 2673.6 & -2972.2 \\
3 & 742.4 & -655.8 \\
\hline
\end{tabular}

TABLE 4: Vibration amplitude of each channel under the S wave motion curve.

\begin{tabular}{lcc}
\hline Signal channel & $\begin{array}{c}\text { Maximum amplitude } \\
(\mu \mathrm{m})\end{array}$ & $\begin{array}{c}\text { Minimum amplitude } \\
(\mu \mathrm{m})\end{array}$ \\
\hline 1 & 634.6 & -423.7 \\
2 & 6706.8 & -7312.9 \\
3 & 903.5 & -1071.4 \\
\hline
\end{tabular}

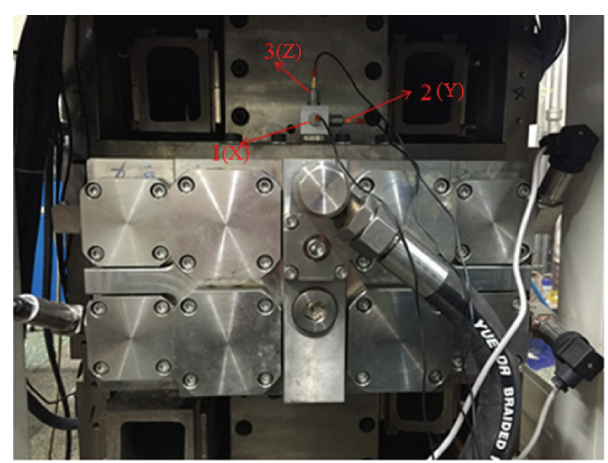

FIGURE 8: Vibration test point.

Though Coinv DASP software, the acceleration, velocity, and displacement of the vibration signal are collected in real time. According to previous dynamic characteristic simulation analysis of the linear motor, the vibration response test of triangle curve and S curve under PVT motion mode have been conducted. The motion period is set as 0.6 seconds, and the stroke is $205 \mathrm{~mm}$. Four groups of linear motor are moving at the phase difference of 90 degrees. After the calculus processing of the collected vibration data, the amplitude distribution in the time domain of the $x$-, $y$-, and $z$-axis is shown in Figure 9.

It can be seen from Figure 9 that the periodic vibration exists in the system and the vibration impact cycle is roughly identical to the system movement cycle. It demonstrates that the main vibration source of the linear-motor-driven water piston pump is continuous high-speed reciprocating motion of the linear motor unit. The vibration impact is derived from the unbalanced torque caused by the thrust of the linear motor. The vibration amplitudes of each channel under the $S$ and triangle curve are shown in Tables 3 and 4, respectively. Compared to the results of three signal channels, the vibration peak appears in number 2 signal channel and the maximum amplitude of triangle and $\mathrm{S}$ curve are $2673.6 \mu \mathrm{m}$ and $6706.8 \mu \mathrm{m}$, respectively. It means that severe vibration occurs in the direction which is perpendicular to the linear motor movement direction. The dampers mounted at the platform bottom and cylinder wall have a good effect to reduce the vibration. From another aspect, the base with a certain degree of flexibility will aggravate the vibration of system. Therefore, the vibration amplitude of number 3 signal channel is greater than that of number 1 .

From the previous parameters debugging of simulation system, it can be known that the following errors of linear motor under triangle curve are lesser than that of $S$ curve. The following error was ultimately reflected in the vibration amplitude of test results. Comparing the vibration amplitudes (as shown in Tables 3 and 4), the vibration of the triangular wave is significantly better than that of S wave, and this is consistent with the simulation results. By adopting triangular motion curve under PVT mode, the cylinder vibration amplitude was reduced $35 \%, 60 \%$, and $18 \%$ in $x$-, $y$-, and $z$ axis direction, respectively.

3.3. Power Spectrum Analysis. Random vibration is the most common type of vibration, and it should be studied when carrying out a vibration-proof design. Power spectrum density (PSD) is an effective method to describe random vibration. Generally, the random vibration is characterized by the power spectral density function, for a time series $\chi(t)$ is defined as the Fourier transform of the correlation function $R_{\chi}(\tau)$ [24]:

$$
G_{\chi y}(\omega)=\frac{1}{2 \pi} \int_{-\infty}^{\infty} R_{\chi y}(\tau) e^{-i \omega \tau} d \tau
$$

The correlation function is used to describe the relationship between the two values of the same signal in the interval $\tau$ and can be written as

$$
R(\tau)=\lim _{T \rightarrow \infty} \frac{1}{T} \int_{0}^{T} x(t) x(t+\tau) d t
$$

where $x(t)$ is the vibration response of any transient $t$.

The PSD is widely used because the modes could be indicated clearly by spectral peaks. Power spectrum is the concept of statistical average random process that is expressed by the signal power with the change of frequency. The horizontal axis unit of power spectrum density plot is $\mathrm{Hz}$, and the vertical axis is $\mathrm{g}^{2} / \mathrm{Hz}$, where $\mathrm{g}^{2}$ represents the mean square value of the acceleration. With the DASP software to analyze the collected data, the power spectrum of the linear-motordriven water piston pump under different motion condition is shown in Figure 10 and the power spectrums of each signal channel are displayed in different graph.

Compared to the graphs of signal channel in the different motion mode, it can be observed that the trend of power spectrum is basically identical. Like the previous analysis, the power spectrum only reserves the amplitude information and lost the phase information. So, the difference lies in the amplitude at the resonance frequency. The amplitudes of each channel under triangular curve are $0.025,0.082$, and $0.078 \mathrm{~g}^{2}$, while the amplitude of each channel under $S$ curve are 0.16 , 0.31 , and $0.36 \mathrm{~g}^{2}$. Obviously, the vibration amplitude of the $S$ wave is $4 \sim 6$ times that of triangular wave. The experimental data show that the vibration under triangular motion curve 
(1D)

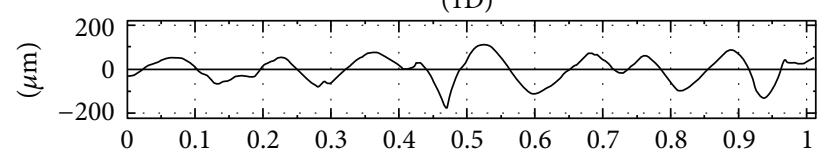

(s)

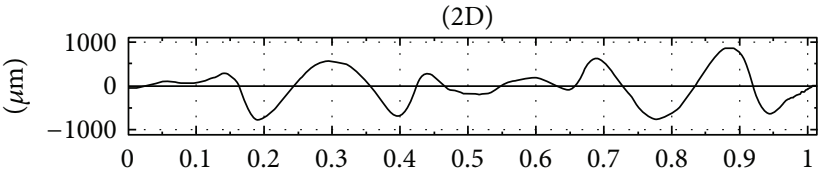

(s)

(3D)

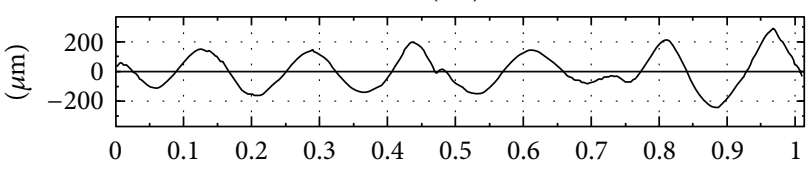

(s)

(a) Triangle curve, PVT motion mode
(1D)

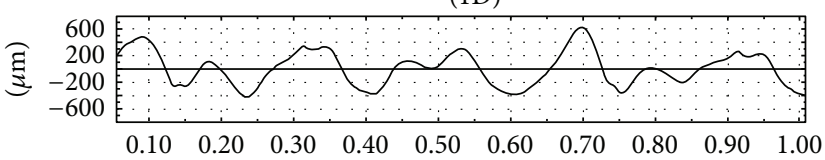

(s)

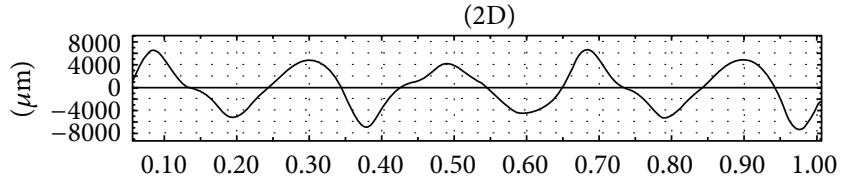

(s)

(3D)

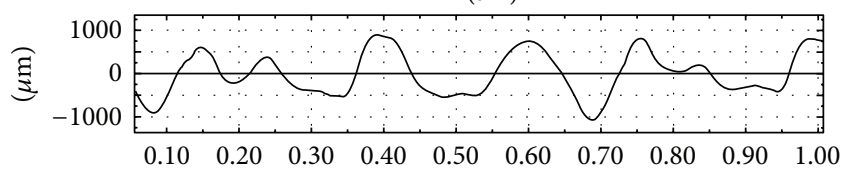

(s)

(b) S curve, PVT motion mode

FIGURE 9: Vibration amplitude distribution in the time domain of the $x$-, $y$-, and $z$-axis.

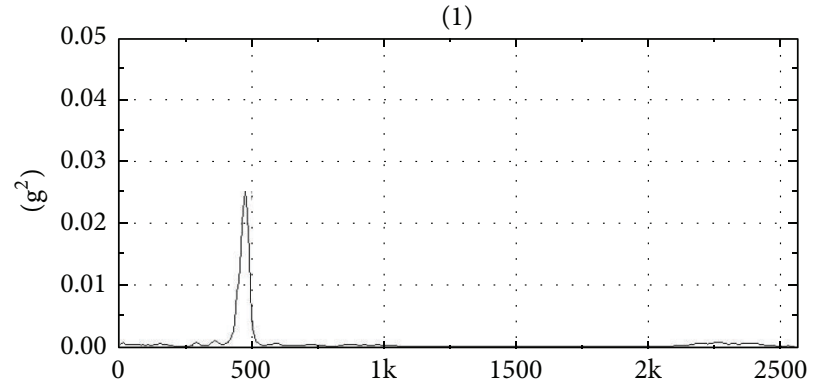

$(\mathrm{Hz})$

(2)

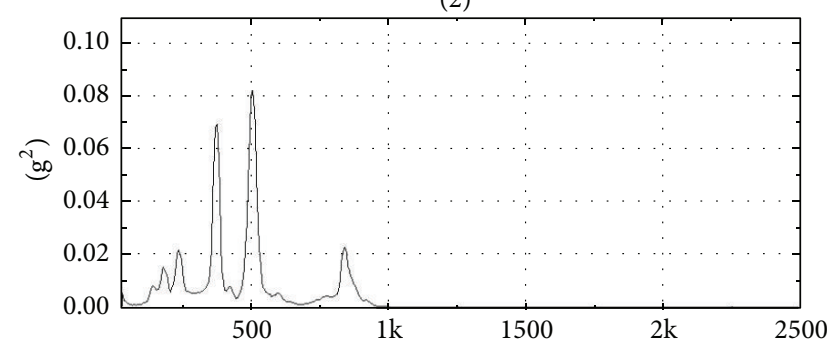

$(\mathrm{Hz})$

(3)

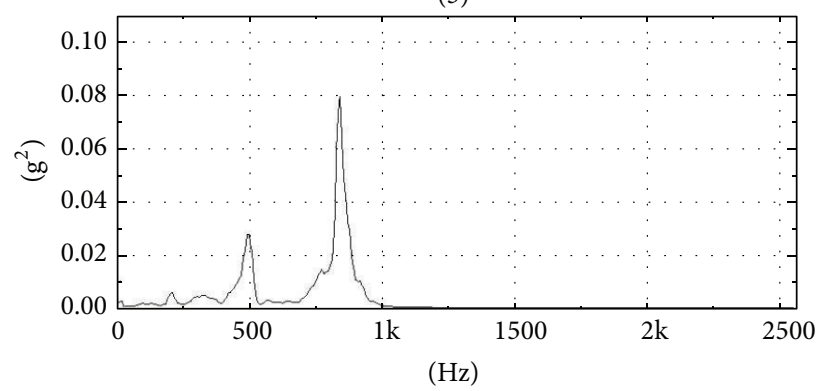

(a) Triangle curve, PVT motion mode

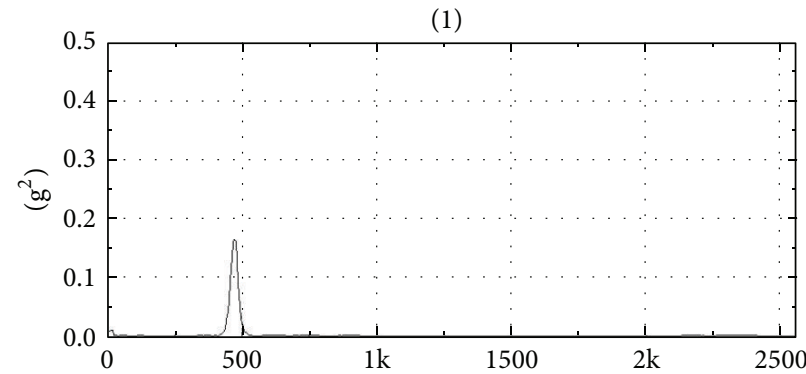

$(\mathrm{Hz})$

(2)

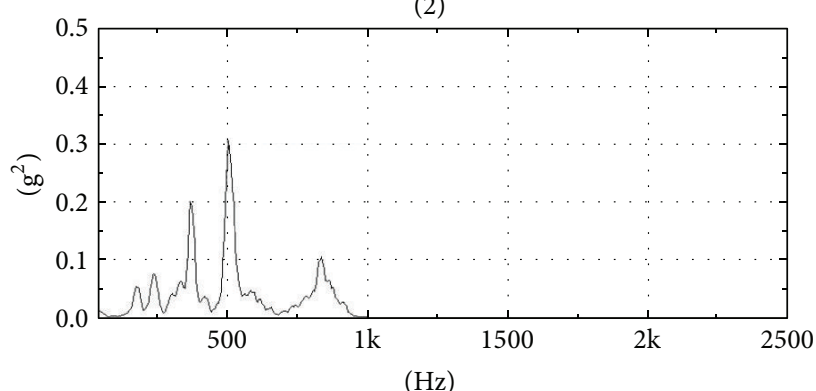

(3)

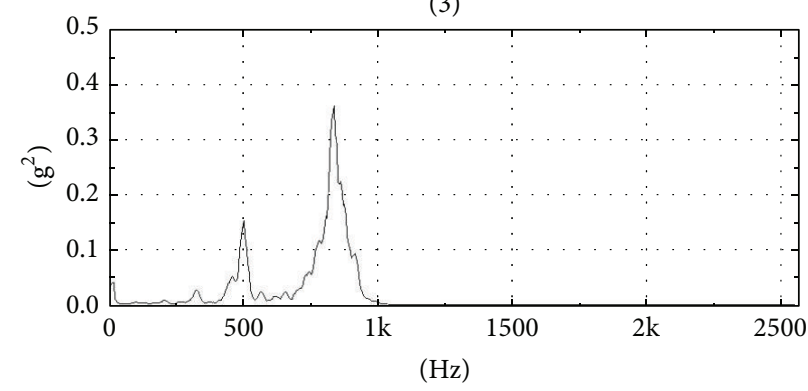

(b) S curve, PVT motion mode

Figure 10: Power spectrum of linear-motor-driven water piston pump system under triangle and S motion curve. 
is much better than that of S curve, which is consistent with the previous simulation conclusion. Different motion curves will affect the following errors of the linear motor, which is reflected in the vibration of the system finally.

It can be seen from Figure 10(a) that, under the triangular wave motion curve, the peak of number 1 signal channel is only one-third the peaks of number 2 and number 3 . The peak frequency of number 1 signal channel (the motion direction of linear motor) only appears near $500 \mathrm{~Hz}$ and has a little difference with the value provided by the FEM analysis. With the dampers equipped on the cylinder body in the motion direction of linear motor, it will inevitably lead to the difference between the simulation results and the experimental data. According to the data collected by number 2 signal channel, the resonance frequency is mainly concentrated in the vicinity of $500 \mathrm{~Hz}$ and $800 \mathrm{~Hz}$. Similarly, the analysis result of number 3 signal channel is essentially consistent with the harmonic analysis result. Therefore, the resonance frequency of linear-motor-driven water piston pump is concentrated upon $500 \mathrm{~Hz}$ and $800 \mathrm{~Hz}$ in the low frequency range. The dampers can change the resonance frequency of the system to a certain extent. During the operation of the linear-motordriven water piston pump, the resonance frequency range detected by simulation analysis and experiment test should be avoided to effectively reduce the vibration.

\section{Conclusion}

Based on the prototype and three-dimensional model of the linear-motor-driven water piston pump, this paper has carried out the vibration characteristic analysis. The finite element analysis software has been employed to perform a static stress, modal, and harmonic analysis. The maximum deformation and equivalent stress of the mechanical structure were measured at the rated working condition. From the results presented in this paper, the important conclusions obtained can be drawn as follows:

(1) The simulation results reveal that the maximum deformation and equivalent stress of the mechanical structure in this pump are $0.15 \mathrm{~mm}$ and $95.398 \mathrm{MPa}$, respectively, which is lower than the yield strength of the material and the allowed deformation. The first-order natural frequency is close to $166.19 \mathrm{~Hz}$, which is much larger than the system motion frequency $(3 \mathrm{~Hz})$, and the modal deformation is about $18.3 \mathrm{~mm}$. And the mode shape under low frequency stage is associated with the eccentricity swing of the piston rod and the maximum deformation is within the acceptable range.

(2) The harmonic analysis and vibration experiment results show that the resonance frequency of linear-motordriven water piston pump is concentrated upon $500 \mathrm{~Hz}$ and $800 \mathrm{~Hz}$ in the low frequency range. The dampers can change the resonance frequency of the system to a certain extent.

(3) The vibration under triangular motion curve is much better than that of S curve, which is consistent with the previous simulation conclusion.

The research provides an effective method to detect the vibration characteristics of the linear-motor-driven water piston pump and also a reference for design and optimization of the piston pump.

\section{Competing Interests}

The authors declare that they have no competing interests.

\section{Acknowledgments}

The authors would like to thank the National Natural Science Foundations of China (nos. 51375018 and 11572012), National High-Tech R\&D (863) Program (no. 2012AA091103), Beijing Natural Science Foundation (no. 3164039), and China Postdoctoral Science Foundation (no. 2015M580946) for their funding for this research.

\section{References}

[1] C. Louis, F. Michael, and G. K. Thomas, "Water hydraulic energy savings vehicle," in Proceedings of the 8th Scandinavian International Conference on Fluid Power (SICFP '03), pp. 117128, Tampere, Finland, May 2003.

[2] H. Y. Yang, J. Yang, and H. Zhou, "Research on materials of piston and cylinder of water hydraulic pump," Industrial Lubrication and Tribology, vol. 55, no. 1, pp. 38-43, 2003 (Chinese).

[3] G. H. Lim, P. S. K. Chua, and Y. B. He, "Modern water hydraulics-the new energy-transmission technology in fluid power," Applied Energy, vol. 76, no. 1-3, pp. 239-246, 2003.

[4] L. Yang, S. Nie, and A. Zhang, "Non-probabilistic wear reliability analysis of swash-plate/slipper of water hydraulic piston motor based on convex model," Journal of Mechanical Engineering Science, vol. 227, no. 3, pp. 609-619, 2013.

[5] F. Yin, S. Nie, Z. Zhang, and X. Zhang, "Research on the sliding bearing pair of water hydraulic axial piston pump," Proceedings of the Institution of Mechanical Engineers, Part C: Journal of Mechanical Engineering Science, vol. 227, no. 9, pp. 2049-2063, 2013.

[6] W. Dong and S. Nie, "Research on motion planning of linear motor driven piston pump," Journal of Chinese Mechanical Engineering, vol. 25, no. 8, pp. 1080-1084, 2014 (Chinese).

[7] Y.-Q. Huang, S.-L. Nie, F. Liu, L. Li, and K. Ma, "Research of the control strategy and vibration test of linear motor driven piston pump for marine application," Journal of Beijing University of Technology, vol. 41, no. 11, pp. 1727-1733, 2015 (Chinese).

[8] J.-H. Shin, "Computational study on dynamic pressure in a swash-plate axial piston pump connected to a hydraulic line with an end resistance," Journal of Mechanical Science and Technology, vol. 29, no. 6, pp. 2381-2390, 2015.

[9] M. K. Bahr, J. Svoboda, and R. B. Bhat, "Vibration analysis of constant power regulated swash plate axial piston pumps," Journal of Sound and Vibration, vol. 259, no. 5, pp. 1225-1236, 2003.

[10] H. X. Chen, P. S. K. Chua, and G. H. Lim, "Adaptive wavelet transform for vibration signal modelling and application in fault diagnosis of water hydraulic motor," Mechanical Systems and Signal Processing, vol. 20, no. 8, pp. 2022-2045, 2006.

[11] H. X. Chen, P. S. K. Chua, and G. H. Lim, "Dynamic vibration analysis of a swash-plate type water hydraulic motor," Mechanism and Machine Theory, vol. 41, no. 5, pp. 487-504, 2006.

[12] H. X. Chen, P. S. K. Chua, and G. H. Lim, "Vibration analysis with lifting scheme and generalized cross validation in fault diagnosis of water hydraulic system," Journal of Sound and Vibration, vol. 301, no. 3-5, pp. 458-480, 2007. 
[13] A. Johansson, J. Ölvander, and J.-O. Palmberg, "Experimental verification of cross-angle for noise reduction in hydraulic piston pumps," Proceedings of the Institution of Mechanical Engineers. Part I: Journal of Systems and Control Engineering, vol. 221, no. 3, pp. 321-330, 2007.

[14] P. Achten, "Dynamic high-frequency behaviour of the swash plate in a variable displacement axial piston pump," Proceedings of the Institution of Mechanical Engineers. Part I: Journal of Systems and Control Engineering, vol. 227, no. 6, pp. 529-540, 2013.

[15] H. Yamada, T. Yano, H. Wakiwaka et al., "Development of high power linear pulse motor for artificial heart," in Proceedings of the IEE Conference Publication, vol. 341, pp. 110-114, London, UK, 1991.

[16] T. X. Mei and R. M. Goodall, "Position control for a subsea pump system driven by a linear motor," Control Engineering Practice, vol. 3, no. 3, pp. 301-311, 1995.

[17] J. Z. Zhang and T. N. Yang, "Experimental research on flow and pressure variation of linear motor driven reciprocating pump," Oil Field Equipment, vol. 38, no. 4, pp. 56-61, 2009 (Chinese).

[18] Y. J. Hou, K. T. Cai, P. Z. Zhang et al., "Research on motion characteristics of double-action tri-linear motor reciprocating pump," Oil Field Equipment, vol. 8, pp. 12-16, 2009 (Chinese).

[19] W. Xiao, X. Zhou, Y. Gu, and S. Zhang, "Performance of linearmotor pumping unit," Acta Petrolei Sinica, vol. 27, no. 5, pp. 112114, 2006 (Chinese).

[20] V. H. Vu and M. Thomas, "Uncertainties on modal parameters by operational modal analysis," Mechanics and Industry, vol. 15, no. 2, pp. 153-158, 2014.

[21] D. Rand, B. C. Ellis, and P. R. Prucnal, "Modal analysis of semiconductor cylinder fibers," IEEE Photonics Technology Letters, vol. 18, no. 1, pp. 31-33, 2006.

[22] A. Minardo, A. Coscetta, S. Pirozzi, R. Bernini, and L. Zeni, "Experimental modal analysis of an aluminum rectangular plate by use of the slope-assisted BOTDA method," Smart Materials and Structures, vol. 22, no. 12, Article ID 125035, 2013.

[23] P. Anedre, "Noise reduction of an axial piston pump by means of structural modification," The Hydraulikund Pneumatik, vol. 48, no. 4, pp. 1-11, 2004.

[24] R. Brincker, "Some elements of operational modal analysis," Shock and Vibration, vol. 2014, Article ID 325839, 11 pages, 2014. 


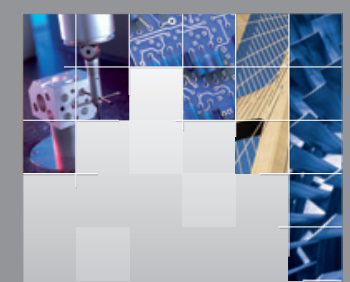

\section{Enfincering}
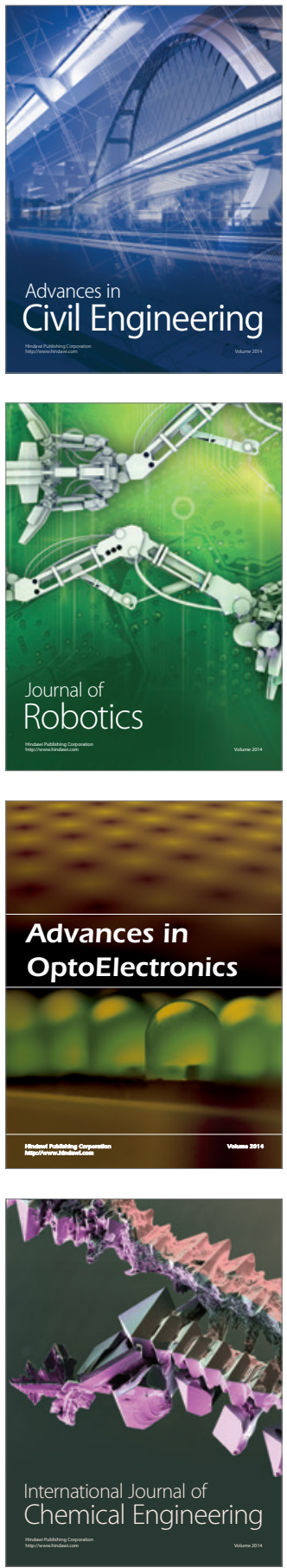

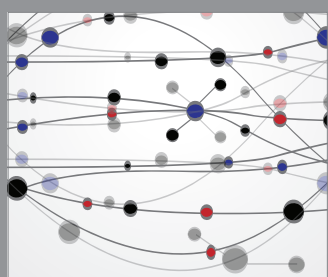

The Scientific World Journal

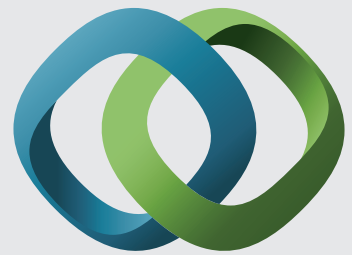

\section{Hindawi}

Submit your manuscripts at

http://www.hindawi.com
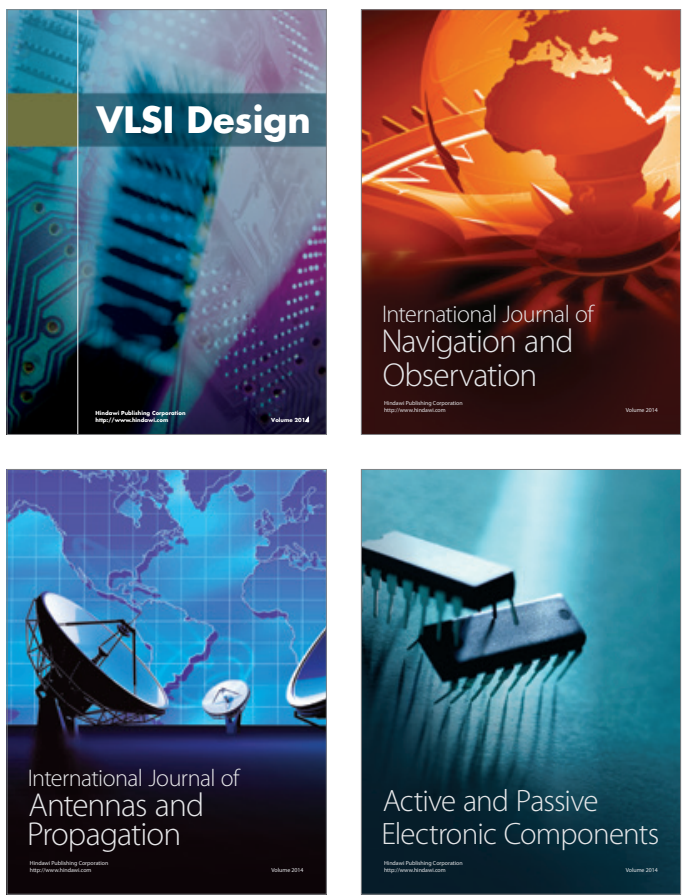
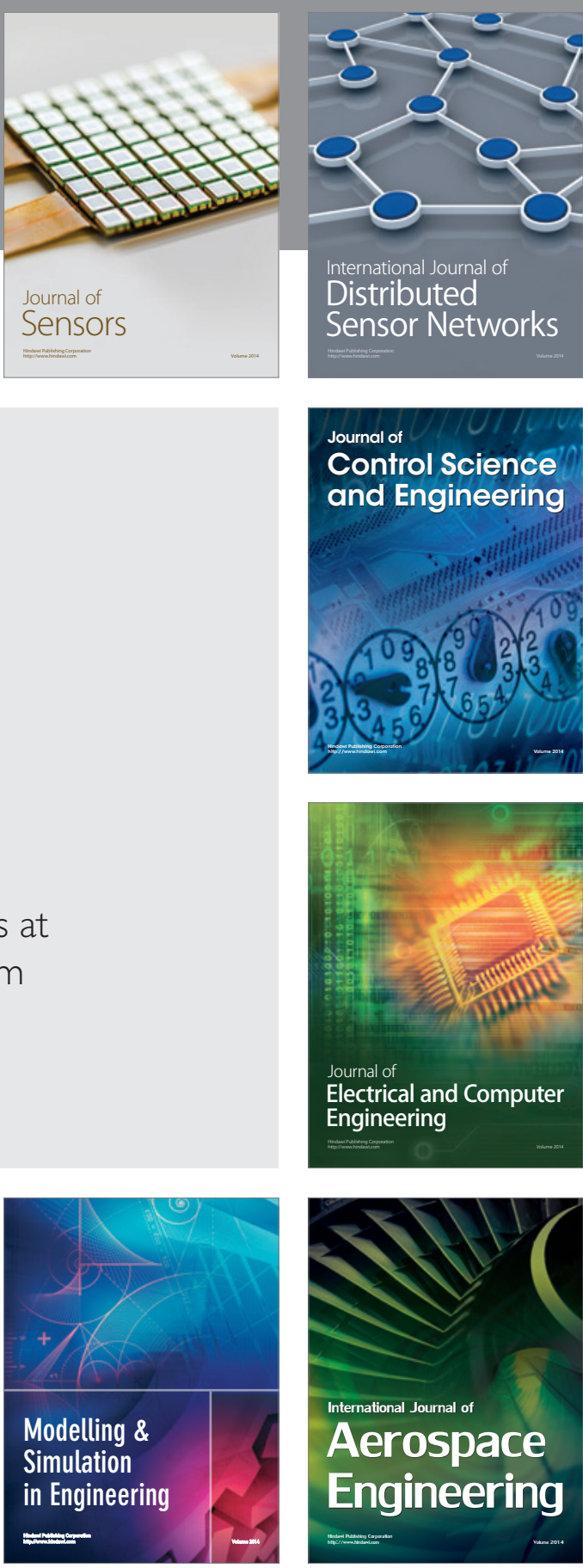

International Journal of

Distributed

Sensor Networks

Journal of

Control Science

and Engineering
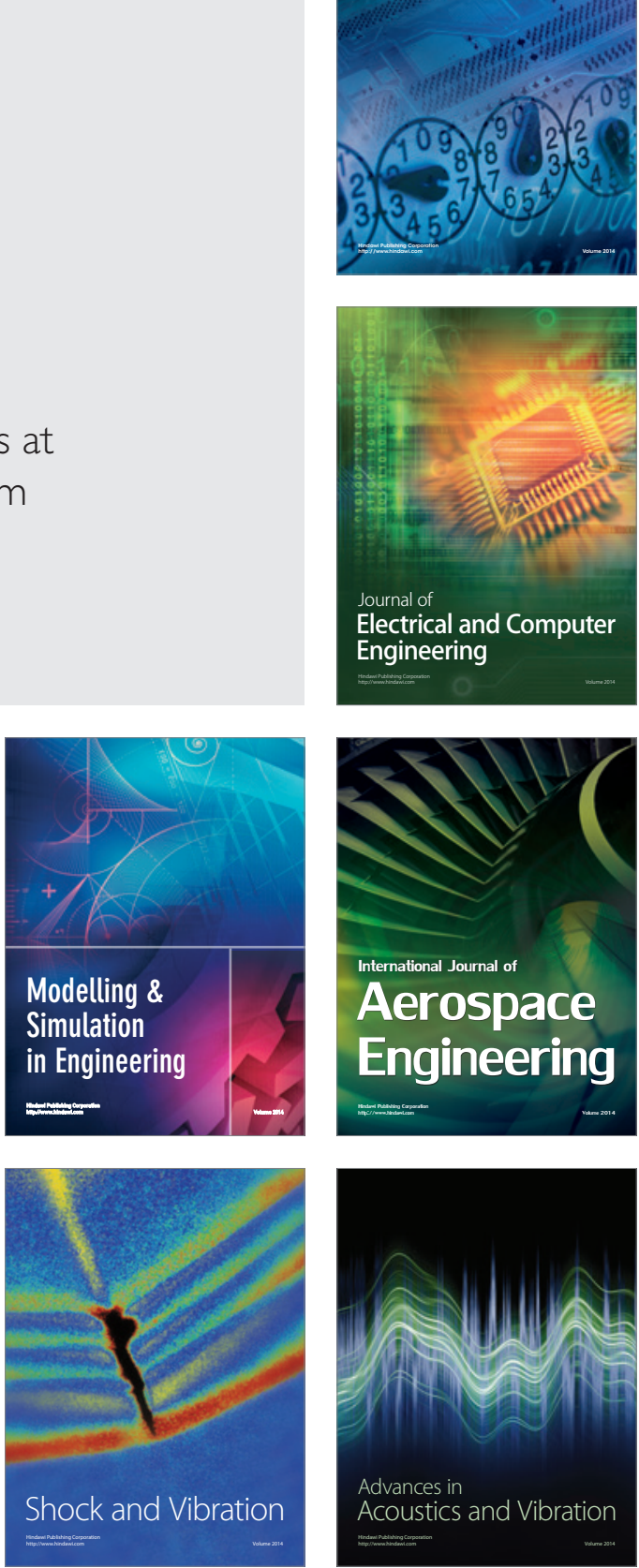